\title{
Valsartan improves mitochondrial function in hearts submitted to acute ischemia
}

\author{
Pedro Monteiro a , Ana I. Duarte ${ }^{\mathrm{b}}$, Lino M. Gonçalves ${ }^{\mathrm{a}, \mathrm{c}, *}$, Luís A. Providência ${ }^{\mathrm{a}, \mathrm{c}}$ \\ ${ }^{a}$ Basic Research Unit in Cardiology-Cardiology Department, Coimbra University Hospital, Praceta Prof. Mota Pinto, 3000-075 Coimbra, Portugal \\ ${ }^{\mathrm{b}}$ Center for Neurosciences of Coimbra, 3004-517 Coimbra, Portugal \\ ${ }^{\mathrm{c}}$ Faculty of Medicine, Coimbra University, 3000-075 Coimbra, Portugal
}

Received in revised form 8 March 2005; accepted 14 June 2005

\begin{abstract}
The effect of valsartan, an angiotensin II-type I receptor blocker, on the mitochondrial function, was studied using an ex vivo animal model (hearts from Wistar rats), perfused in a Langendorff system and then submitted to global acute ischemia. Parameters evaluated were: membrane electrical potential $\left(\Delta \Psi\right.$, using a tetraphenylphosphonium-TPP ${ }^{+}$-electrode), oxygen consumption by the respiratory chain (Clark-type $\mathrm{O}_{2}$ electrode), phosphorylation lag phase (time necessary to phosphorylate a fixed amount of ADP) and ATP/ADP ratio (adenine nucleotides quantified by high-pressure liquid chromatography-HPLC). Valsartan acts preferentially in the phosphorylation, increasing ATP/ADP ratios (succinate: $1.6 \pm 0.4$ versus $0.5 \pm 0.1-P<0.05$; ascorbate $/ N, N, N^{\prime}, N^{\prime}$-tetramethyl- $P$-phenylenodiamine-TMPD: $1.1 \pm 0.2$ versus $0.4 \pm 0.1-p<0.05$ versus ischemia in the absence of valsartan) and decreasing lag phase (glutamate/malate: $50.0 \pm 9.6 \mathrm{~s}$ versus $127.2 \pm 19.03 \mathrm{~s}-84.6 \pm 16.2 \%$ versus $215.3 \pm 32.2 \% ; P=0.01$; succinate: $111.8 \pm 33.1 \mathrm{~s}$ versus $275.73 \pm 45.99 \mathrm{~s}-168.2 \pm 49.8 \%$ versus $414.9 \pm 69.2 \% ; P=0.02$ or ascorbate/TMPD: $11.0 \pm 3.9 \mathrm{~s}$ versus $62.4 \pm 11.63 \mathrm{~s}-34.9 \pm 12.4 \%$ versus $198.1 \pm 36.9 \%$; $P=0.001$ versus ischemia in the absence of valsartan). This enables a higher energy production in hearts submitted to acute ischemia, for which having energy becomes critical to preserve mitochondrial function. These mechanisms allow us to better understand valsartan cytoprotection in ischemic cardiomyopathy.
\end{abstract}

(C) 2005 Elsevier B.V. All rights reserved.

Keywords: Ischemia; Valsartan; Mitochondria; Heart; Cell biology; Cardioprotection

\section{Introduction}

Mitochondria are the main cellular energy production centers. Their importance regarding cell metabolism is proportional to cellular energy requirements. Cardiomyocytes, the paradigm of high energy consuming cells, have their survival tightly connected to a normal mitochondrial function. In turn, mitochondria are commonly a major target for cardiomyocyte stress factors, like ischemia.

\footnotetext{
* Corresponding author. Basic Research Unit in Cardiology-Cardiology Department, Coimbra University Hospital, Praceta Prof. Mota Pinto, 3000075 Coimbra, Portugal. Tel.: +351 239 400414/721153; fax: +351 239 780552 .

E-mail address: lgoncalv@ci.uc.pt (L.M. Gonçalves).
}

Valsartan is a tetrazol-byphenil-valinic derivative of losartan, structurally characterized by the presence of a sole heterocyclic structure (Bauer and Reams, 1995). Functionally, valsartan is a highly selective non-competitive angiotensin II-type I $\left(\mathrm{AT}_{1}\right)$ receptor antagonist $(30,000$ times higher affinity for $\mathrm{AT}_{1}$ than for angiotensin II-type 2 receptors$\mathrm{AT}_{2}$ ) (Criscione et al., 1993). Valsartan has showed to be effective in decreasing blood pressure values (in monotherapy or in combination with other anti-hypertensive drugs) and treating heart failure (on top of optimal therapy, including angiotensin converting enzyme inhibitors) (Kim et al., 2001; Multani et al., 2001a,b; Palatini et al., 2001).

Studies performed in animal models of acute myocardial infarction showed that valsartan decreases both reactive oxygen species production (Kuno et al., 2002) 
and ventricular remodeling (Yu et al., 2001). In order to assess if the post-acute myocardial infarction positive effects also occur in humans, a large-scale randomized clinical trial was recently conducted (Pfeffer et al., 2003a,b) and its results clearly support the reported animal data. In animal models of heart failure, valsartan showed a positive effect regarding remodeling (even in animals on angiotensin converting enzyme inhibitors) (Richer et al., 2001), therefore improving left ventricular function and survival (Kim et al., 2001). These effects can be bradykinin (valsartan increases bradykinin levels) (Multani et al., 2001a,b) and nitric oxide-mediated (Liu et al., 2002) and were partially confirmed in heart failure patients (Cohn and Tognoni, 2001). In animal models of hypertension, valsartan was shown to have an anti-apoptotic effect (der Sarkissian et al., 2003). Although many cellular actions of valsartan are well established, its impact on mitochondrial function during acute myocardial ischemia remains largely unknown.

Therefore, our aim was to assess if valsartan could have mitochondria as intracellular targets against damage caused by global ischemia, using an ex vivo model of perfusion with a Langendorff system.

\section{Material and methods}

This investigation conformed with the Guide for the Care and Use of Laboratory Animals published by the US National Institutes of Health-NIH publication No. 85-23, revised 1996-(National Research Council, 1996) and it was approved by the Ethics Committee of the Centre for Neuroscience and Cell Biology of Coimbra, where the experimental work took place. All compounds were of the purest quality available and were ordered from Sigma Chemical Co. (St. Louis, MO) or Merck (Darmstadt, Germany), except for valsartan that was obtained from Novartis (Basel, Switzerland).

\subsection{Experimental groups}

Thirty Wistar rats were randomly assigned into three experimental groups: control $(n=10)$, ischemia $(n=10)$ and ischemia + valsar$\tan 1 \mathrm{nM}(n=10)$.

\subsection{Assembly of the ex vivo perfusion system}

Wistar rats, weighing around $300 \mathrm{~g}$, were killed by $\mathrm{CO}_{2}$ inhalation. Each heart was rapidly excised and mounted in a Langendorff perfusion apparatus (model UP-100 from Hugo Sachs Elektronik, Germany) and then perfused at a constant flow $(25 \mathrm{~mL} / \mathrm{min})$ with a Krebs modified solution $(\mathrm{NaCl} 118 \mathrm{mM}, \mathrm{KCl} 4.7 \mathrm{mM}$, $\mathrm{KH}_{2} \mathrm{PO}_{4} 1.2 \mathrm{mM}, \mathrm{NaHCO}_{3} 25 \mathrm{mM}, \mathrm{MgSO}_{4} 1.2 \mathrm{mM}, \mathrm{Na}_{2}$ EDTA 0.5 $\mathrm{mM}$, glucose $10 \mathrm{mM}$ and $\mathrm{CaCl}_{2} 3 \mathrm{mM}$; $\mathrm{pH}$ 7.4) and gassed with carbogen $\left(95 \% \mathrm{O}_{2}-5 \% \mathrm{CO}_{2}\right)$. Temperature was continuously monitored and maintained at $37{ }^{\circ} \mathrm{C}$ (via a thermostatic bath) throughout the perfusion period ( $180 \mathrm{~min}$ for the control group and $60 \mathrm{~min}$ for the remaining groups); $\mathrm{pH}$ was also continuously monitored with a $\mathrm{pH}$ electrode and kept stable at 7.35-7.45 during this period. Valsartan at $1 \mathrm{nM}$ was added to the Krebs modified solution in the respective experimental groups (after pilot experiments, this dose was chosen because it was the lowest dose with positive impact on mitochondrial function). Left ventricular pressure and heart rate were recorded at regular intervals. After the initial perfusion, all rat hearts, with the exception of the control group, were submitted to 120 min of ischemia at $37{ }^{\circ} \mathrm{C}$ in a solution identical to that of the perfusion period, but without glucose and carbogen (at the beginning of the ischemic period, the perfusion flow - with carbogen - was stopped and the hearts were submitted to no-flow ischemia; in order to maintain temperature $-37{ }^{\circ} \mathrm{C}$ - , they were immersed in Krebs modified solution-without glucose and carbogen-that was previously gassed with nitrogen). The time of ischemia was chosen after performing pilot experiments, designed to determine the time of ischemia (without reperfusion) needed to significantly impair cardiac mitochondrial function.

\subsection{Preparation of the biological material}

\subsubsection{Isolation of rat heart mitochondria}

At the end of the perfusion and ischemia periods, the mitochondrial fraction from each rat heart was prepared according to the method described by Rickwood et al. (1987a). All the parameters of mitochondrial function were assessed in the isolated mitochondrial fraction.

\subsection{Laboratorial methods used}

\subsubsection{Determination of protein concentration}

The protein concentration of the mitochondrial fraction was determined using the biuret colorimetric method (Gornall et al., 1949).

\subsubsection{Determination of the mitochondrial membrane potential}

Membrane electrical potential $(\Delta \Psi)$ was determined through the permanent recording of the distribution of the lipophilic cation tetraphenylphosphonium $\left(\mathrm{TPP}^{+}\right)$across the inner mitochondrial membrane. This was done with an electrode sensitive to $\mathrm{TPP}^{+}$prepared in our laboratory, according to the principles established by Kamo et al. (1979). Reactions took place at a constant temperature of $25^{\circ} \mathrm{C}$, in an open and thermostable reaction chamber, using $1 \mathrm{ml}$ of reaction solution (sucrose $130 \mathrm{mM}, \mathrm{KCl} 50 \mathrm{mM}, \mathrm{MgCl}_{2} 5 \mathrm{mM}, \mathrm{KH}_{2} \mathrm{PO}_{4} 5$ $\mathrm{mM}$ and ( $N$-[2-hydroxyethyl] piperazine- $N^{\prime}$-[2-ethanosulphonic]) acid (HEPES) $5 \mathrm{mM}, \mathrm{pH} 7.2$ ), supplemented with $3 \mu \mathrm{M} \mathrm{TPP}^{+}$and the mitochondrial suspension (volume corresponding to $2 \mathrm{mg}$ of protein, as determined by the biuret method). The determination of mitochondrial $\Delta \Psi$ was performed using the method described by Muratsugu et al. (1977) and Kamo et al. (1979). The matrix volume was assumed to be $1.1 \mu \mathrm{l} / \mathrm{mg}$ of protein.

\subsubsection{Evaluation of mitochondrial respiratory activity}

All the assays were performed at $25{ }^{\circ} \mathrm{C}$, in a closed reaction chamber, with stable temperature and $1 \mathrm{ml}$ capacity.

Oxygen consumption was evaluated polarographically with an $\mathrm{O}_{2}$ electrode (Yellow Springs Instruments, Co.), Clark type, connected to a Kipp \& Zonen recorder, through a command unit manufactured at our laboratory. Electrode calibration was done according to the protocol described by Rickwood et al. (1987b).

Reactions were initiated by adding the mitochondrial suspension to the reaction solution (as previously described). The later addition of the respiratory substrate [glutamate $10 \mathrm{mM}+$ malate $5 \mathrm{mM}$, succinate $5 \mathrm{mM}$ or ascorbate $5 \mathrm{mM}+N, N, N^{\prime}, N^{\prime}$-tetramethyl- $P$ - 
phenylenodiamine (TMPD) $0.25 \mathrm{mM}$ ] induced an increase in $\mathrm{O}_{2}$ consumption by the mitochondrial fraction. Respiratory state 3 (characterized by a higher and faster $\mathrm{O}_{2}$ consumption) was then induced by the addition of adenosine diphosphate (ADP) $250 \mathrm{nmol}$ (62.5 nmol when using ascorbate/TMPD). After all ADP was consumed, the reaction returned to a slower velocity, respiratory state 4. Respiratory control ratio was evaluated as the quotient between state 3 and state 4 .

\subsubsection{Evaluation of the ATP/ADP ratio}

The protocol for extraction of the adenine nucleotides (ATP, ADP and AMP) was as follows: at the end of one phosphorylation cycle induced by the addition of ADP, $250 \mu \mathrm{l}$ of the final respiratory medium was collected (corresponding to $0.5 \mathrm{mg}$ of mitochondrial protein) and added to $250 \mu 1$ of $\mathrm{HClO}_{4} 0.6 \mathrm{M}$ (with $25 \mathrm{mM}$ of EGTA). Five minutes later, the mixture was agitated in a vortex (to obtain a protein-free sample) and centrifuged for $2 \mathrm{~min}$ at $10,000 \times g$ in an Eppendorf centrifuge (at $0{ }^{\circ} \mathrm{C}$ ). The pellet was then removed and the supernatant was neutralised with $\mathrm{KOH} 3 \mathrm{M}+$ Tris $1.5 \mathrm{M}$ and then centrifuged at $10,000 \times g$ for another $2 \mathrm{~min}$. All procedures were conducted at low temperature $\left(0-4{ }^{\circ} \mathrm{C}\right)$. The adenine nucleotides were separated by high-pressure liquid chromatography (HPLC), reverse phase (Stocchi et al., 1985), in a Beckman Gold chromatograph, with a model 126 pump and a variable UV detector (model 166), controlled by a computer. The detection wavelength was $254 \mathrm{~nm}$, using a Licrosphere $100 \mathrm{RP}-18$ column $(5 \mathrm{~mm})$ made by Merck (Darmstad, Germany). The protocol used consisted of isocratic elution with potassium phosphate buffer $(100 \mathrm{mM}$; $\mathrm{pH} 6.5)$ and methanol $1 \%$. The flow rate was $1.25 \mathrm{ml} / \mathrm{min}$ for $5 \mathrm{~min}$ (to achieve nucleotide separation) and the detection limit for each compound was 3 to 5 pmol. The ATP/ADP ratio was then determined.

\subsection{Statistical analysis}

Results are presented as means \pm S.E.M. (raw data or expressed as percentage of control), for the number of results indicated.
Results were analyzed using the one-way ANOVA test. The level of significance used was $P<0.05$.

\section{Results}

As it was previously demonstrated by several authors (Corbucci, 2000; Ylitalo et al., 2001; Marin-Garcia and Goldenthal, 2002), our results clearly show that oxidative phosphorylation is very sensitive to ischemia, which dramatically affects mitochondrial respiratory chain (Fig. 1), as it can be shown by the decrease in the respiratory control ratio [that is, the ratio between the oxygen consumption during active phosphorylation (state 3 ) and after active phosphorylation (state 4)], when compared to the value obtained in mitochondria from the control group $(2.71 \pm 0.42$ versus $1.51 \pm 0.13 ; P=0.0002)$. Valsartan $(1 \mathrm{nM})$ did not significantly affected this parameter when using glutamate/malate as energy substrate (respiratory control ratio $-1.56 \pm 0.1$ versus $1.51 \pm 0.13$; $P=$ not significant), although there was a significant increase in oxygen consumption by mitochondria from valsartan-treated hearts, both in state $3(115.5 \pm 17.2$ versus $73.6 \pm 7.0$ natm oxygen $/ \mathrm{min} / \mathrm{mg}$ protein; $P<0.05)$ and state $4(73.4 \pm 9.1$ versus $49.8 \pm 6.0 \mathrm{natm}$ oxygen $/ \mathrm{min} / \mathrm{mg}$ protein; $P<0.05)$ of mitochondrial respiration (Table 1).

When testing glutamate/malate as energy substrate, a decrease in mitochondrial membrane electrical potential $(\Delta \Psi)$, determined by a $\mathrm{TPP}^{+}$-sensitive electrode, was observed in mitochondria from the hearts of the ischemic group, when compared to those of the control group $(209.1 \pm 1.4$ versus $186.7 \pm 3.4 \mathrm{mV}$; $P=0.000001)$. A similar result was found when using succinate $(211.3 \pm 3.2$ versus $187.2 \pm 4.7 \mathrm{mV} ; P<0.05)$ and ascorbate/TMPD $(209.1 \pm 2.5$ versus $189.2 \pm 4.0 \mathrm{mV} ; P<0.05)$ as energy substrates. Valsartan significantly improved $\Delta \Psi$, when glutamate/malate was used as energy substrate $(206.9 \pm 3.0$ versus $186.7 \pm 3.4 \mathrm{mV}$; $P=0.01)$. Similar results were obtained when using succinate (203.5 \pm 4.2 versus $187.2 \pm 4.7 \mathrm{mV} ; P<0.05)$. When ascorbate/

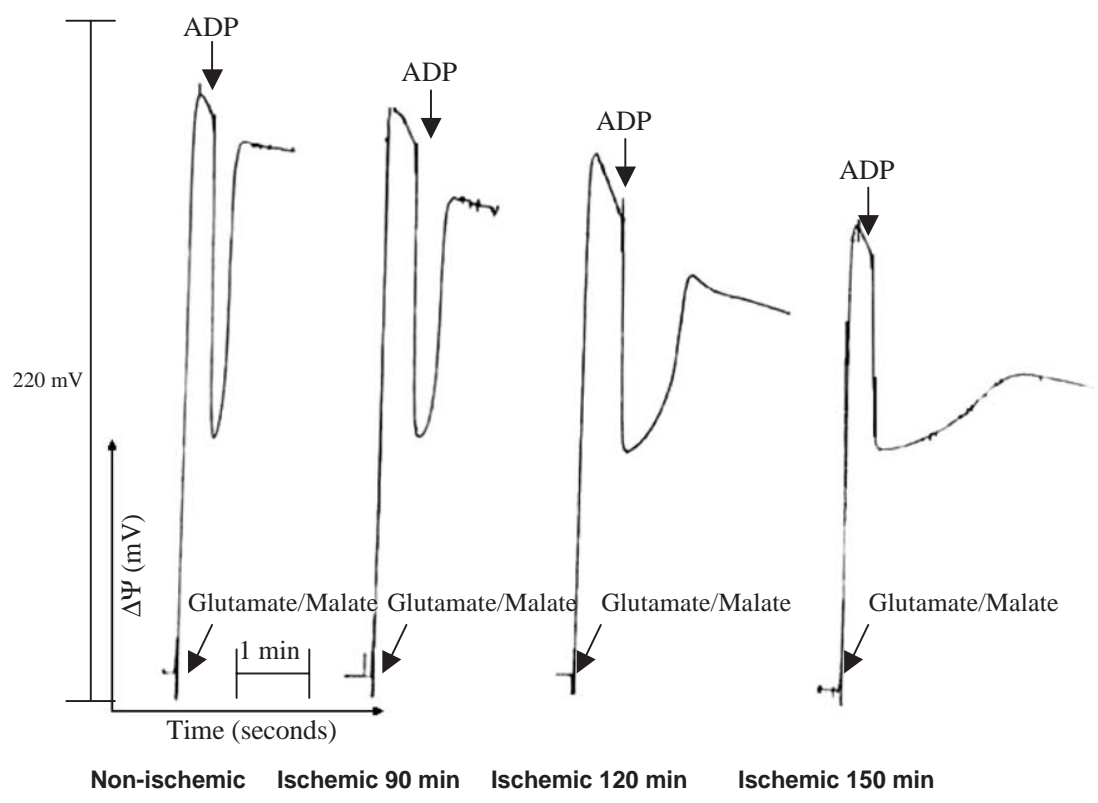

Fig. 1. Typical sample for the mitochondrial membrane potential and phosphorylation time for different periods of ischemia. 
Table 1

Oxygen consumption in states 3 and 4 of mitochondrial respiration, using glutamate/malate as energy substrate

\begin{tabular}{llll}
\hline Parameters/groups & Control & Ischemic & Valsartan \\
\hline Oxygen consumption—state 3 (natm oxygen $/ \mathrm{min} / \mathrm{mg}$ protein) & $97.7 \pm 10.4$ & $73.6 \pm 7.0^{\mathrm{a}}$ & \\
Oxygen consumption—state 4 (natm oxygen/min/mg protein) & $36.9 \pm 2.5$ & $49.8 \pm 6.0^{\mathrm{a}}$ & $115.5 \pm 17.2^{\mathrm{b}}$ \\
Respiratory control ratio & $2.71 \pm 0.42$ & $1.51 \pm 0.13^{\mathrm{a}}$ & $73.4 \pm 9.1^{\mathrm{b}}$ \\
ADP/oxygen & $2.79 \pm 0.3$ & $1.45 \pm 0.22^{\mathrm{a}}$ & $1.56 \pm 0.1$ \\
\hline
\end{tabular}

${ }^{\mathrm{a}} P<0.05$ versus the control group and ${ }^{\mathrm{b}} P<0.05$ versus the ischemic group.

TMPD was used, valsartan also increased $\Delta \Psi(196.0 \pm 1.9$ versus $189.2 \pm 4.0 \mathrm{mV})$, although without reaching statistical significance $(P=0.17)$ - Table 2 .

Another parameter evaluated was the time needed to phosphorylate a fixed amount of ADP (phosphorylation time). The shorter it is, the faster a phosphorylation cycle is completed. Independently of the energy substrate used, we have observed a significant increase in the phosphorylation time when using mitochondria from the hearts of the ischemic group, compared with mitochondria from the control group (glutamate/malate: $59.1 \pm 6.8$ versus $127.2 \pm 19.0 \mathrm{~s}-P=0.001$; succinate: $66.5 \pm 6.4$ versus $275.7 \pm 46.0 \mathrm{~s}-P=0.0001$; ascorbate/TMPD: $31.5 \pm 2.1$ versus $62.4 \pm 11.6 \mathrm{~s}-P=0.001)$. When compared to the ischemic group, mitochondria from the hearts treated with valsartan were able to significantly decrease lag phase and that was consistent regardless of the energy substrate used (glutamate/malate: $50.0 \pm 9.6$ versus $127.2 \pm 19.0 \mathrm{~s}-P=0.01$; succinate: $111.8 \pm 33.1$ versus $275.7 \pm 46.0$ $\mathrm{s}-P=0.02$; ascorbate/TMPD: $11.0 \pm 3.9$ versus $62.4 \pm 11.6 \mathrm{~s}-$ $P=0.001$ ) - Table 3 .

As previously described, the ATP/ADP ratio was also assessed, for each of the energy substrates used (adenine nucleotides - AMP, ADP and ATP were measured after a phosphorylation cycle, using HPLC). Once again, the mitochondria from the ischemic group were shown to have inferior ATP/ADP ratio when compared to mitochondria from the control group, regardless of the substrate used (glutamate/malate: $27.5 \pm 8.9$ versus $10.9 \pm 1.3-P<0.05$; succinate: $4.4 \pm 0.7$ versus $0.5 \pm 0.1-P<0.05$; ascorbate/TMPD: $1.3 \pm 0.5$ versus $0.4 \pm 0.1-P<0.05)$-Table 4 . When compared to

Table 2

Comparison between maximal electrical potential $(\Delta \Psi)$ in the ischemic and valsartan-treated hearts, after the addition of the energy substrate to the reaction medium containing rat heart mitochondria

\begin{tabular}{ll}
\hline Parameters/groups & Electrical potential $(\mathrm{mV})$ \\
\hline Glutamate/malate & \\
Control & $209.1 \pm 1.4$ \\
Ischemic & $186.7 \pm 3.4^{\mathrm{a}}$ \\
Valsartan & $206.9 \pm 3.0^{\mathrm{b}}$ \\
& \\
Succinate & \\
Control & $211.3 \pm 3.2$ \\
Ischemic & $187.2 \pm 4.7^{\mathrm{a}}$ \\
Valsartan & $203.5 \pm 4.2^{\mathrm{b}}$ \\
& \\
Ascorbate/TMPD & \\
Control & $209.1 \pm 2.5$ \\
Ischemic & $189.2 \pm 4.0^{\mathrm{a}}$ \\
Valsartan & $196.0 \pm 1.9$
\end{tabular}

A - glutamate/malate; B - succinate; C - ascorbate/TMPD. Values are presented in $\mathrm{mV}$.

${ }^{\mathrm{a}} P<0.05$ versus the control group and ${ }^{\mathrm{b}} P<0.05$ versus the ischemic group. the ischemic group, mitochondria from valsartan-treated hearts showed a significantly higher ATP / ADP ratio, when succinate and ascorbate/TMPD were used as energy substrates (glutamate/ malate: $10.0 \pm 8.6$ versus $10.9 \pm 1.3-P=$ not significant; succinate: $1.6 \pm 0.4$ versus $0.5 \pm 0.1-P<0.05$; ascorbate/TMPD: $1.1 \pm 0.2$ versus $0.4 \pm 0.1-P<0.05)$. When using glutamate/malate, ratios were similar in both experimental groups (10.0 \pm 8.6 versus $10.9 \pm 1.3 ; P=$ not significant)-Table 4 .

\section{Discussion}

Valsartan, in the concentration used in this experimental protocol $(1 \mathrm{nM})$, revealed a beneficial effect, although unevenly distributed by the oxidative and phosphorylative systems. This statement is validated by a cautious analysis of the results obtained: in parameters assessing the phosphorylative system, namely phosphorylation time and ATP/ADP ratios, improvements were statistically significant (except for ATP/ADP ratio when glutamate/malate was used), resulting in an increase of $\Delta \Psi$, independently of the energy substrate used. On the contrary, no improvement was seen on respiratory control ratio values due to a balanced increase in oxygen consumption in ADP-stimulated oxygen consumption during the active phosphorylation (energy substrate-dependent) - state 3- and during the phase after the active phosphorylation-state 4 .

Table 3

Comparison of the phosphorylation time in the ischemic and valsartantreated hearts, after the addition of the energy substrate to the reaction medium containing rat heart mitochondria

\begin{tabular}{lc}
\hline Parameters/groups & Lag phase (s) \\
\hline Glutamate/malate & $59.1 \pm 6.8$ \\
Control & $127.2 \pm 19.0^{\mathrm{a}}$ \\
Ischemic & $50.0 \pm 9.6^{\mathrm{b}}$ \\
Valsartan & \\
Succinate & \\
Control & $66.5 \pm 6.4$ \\
Ischemic & $275.7 \pm 46.0^{\mathrm{a}}$ \\
Valsartan & $111.8 \pm 33.1^{\mathrm{b}}$ \\
& \\
Ascorbate/TMPD & $31.5 \pm 2.1$ \\
Control & $62.4 \pm 11.6^{\mathrm{a}}$ \\
Ischemic & $11.0 \pm 3.9^{\mathrm{b}}$ \\
Valsartan & \\
\hline A - glutamate/malate; B - succinate C - ascorbate/TMPD. Values are $^{\text {presented in s. }}$ & \\
${ }^{\mathrm{a}} P<0.05$ versus the control group and ${ }^{\mathrm{b}} P<0.05$ versus the ischemic group.
\end{tabular}


Table 4

Levels of ADP, ATP and their ratio, for each experimental group (control, ischemic and valsartan) and for each energy substrate used (glutamate/ malate, succinate and ascorbate/TMPD), after the conclusion of the phosphorylation cycle

\begin{tabular}{|c|c|c|c|}
\hline Parameters/groups & $\begin{array}{l}\text { ADP } \\
\text { (nmol/mg protein) }\end{array}$ & $\begin{array}{l}\text { ATP } \\
\text { (nmol/mg protein) }\end{array}$ & $\begin{array}{l}\mathrm{ATP} / \mathrm{ADP} \\
\text { ratio }\end{array}$ \\
\hline \multicolumn{4}{|l|}{ Glutamate/malate } \\
\hline Control & $2454 \pm 470$ & $67510 \pm 20420$ & $27.5 \pm 8.9$ \\
\hline Ischemic & $4855 \pm 1114$ & $52930 \pm 6865$ & $10.9 \pm 1.3^{\mathrm{a}}$ \\
\hline Valsartan & $8513 \pm 2343$ & $85074 \pm 10336$ & $10.0 \pm 8.6$ \\
\hline \multicolumn{4}{|l|}{ Succinate } \\
\hline Control & $14755 \pm 2987$ & $64292 \pm 22358$ & $4.4 \pm 0.7$ \\
\hline Ischemic & $74454 \pm 4832$ & $38979 \pm 10166$ & $0.5 \pm 0.1^{\mathrm{a}}$ \\
\hline Valsartan & $30653 \pm 8156$ & $49694 \pm 12231$ & $1.6 \pm 0.4^{b}$ \\
\hline \multicolumn{4}{|l|}{ Ascorbate/TMPD } \\
\hline Control & $5234 \pm 792$ & $6688 \pm 1930$ & $1.3 \pm 0.5$ \\
\hline Ischemic & $8597 \pm 1175$ & $3158 \pm 519$ & $0.4 \pm 0.1^{\mathrm{a}}$ \\
\hline Valsartan & $5358 \pm 2372$ & $6118 \pm 1862$ & $1.1 \pm 0.2^{\mathrm{b}}$ \\
\hline
\end{tabular}

${ }^{\mathrm{a}} P<0.05$ versus the control group and ${ }^{\mathrm{b}} P<0.05$ versus the ischemic group.

These results allowed us to complement findings from other studies, which have already shown valsartan to have a positive impact in the setting of acute ischemia (post-acute myocardial infarction), by decreasing reactive oxygen species production (Kuno et al., 2002). Our data clearly show that, by also improving and accelerating ATP production, valsartan has a positive effect on the cellular and subcellular events that take place during acute ischemia. A shorter lag phase is synonymous of faster ADP phosphorylation; this represents a clear advantage, as the ionic gradients can be more rapidly restored once oxygen is added to the system and mitochondria resume ATP pro-duction (that is, in turn, also improved). Several authors, using animal models or human patients, clearly showed that valsartan decreases reactive oxygen species production (Ku-no et al., 2002) and has anti-apoptotic effects (der Sarkissian et al., 2003). Being ischemia an imbalance between energy supply and demand and being the mitochondria the main site of energy production within the cell, we hypothesized that valsartan, by allowing a faster and higher ATP production in the ischemic myocardium, can contribute to the preservation of the mitochondrial function (as our data regarding electrical potential show, being the preservation of electrical potential energy-dependent and membrane integrity-dependent). Being the mitochondria both a major potential reactive oxygen species producer and reactive oxygen species target, an im-proved mitochondrial function is synonymous of lower re-active oxygen species production (or else mitochondrial membrane integrity would be lost by lipoperoxidation and/or by mitochondrial permeability transition induction, a phenomenon that is reactive oxygen species-dependent) (Oliveira et al., 2003) and, therefore, improved cell survival (because reactive oxygen species are a major inducer of cell death, either by necrosis, if there is a massive decrease in energy production, or by apoptosis, because mitochondrial permeability transition leads to cytochrome $c$ release from the mitochondria and caspase cascade activation). The results of the recently published VALIANT trial (Pfeffer et al., 2003a,b) provide the clinical support to this hypothesis, by demonstrating the significant impact of val-sartan on left ventricular function and long-term patient survival.

Previously published papers (Multani et al., 2001a,b; Liu et al., 2002) supported the idea that $\mathrm{AT}_{1}$-receptor antagonists can act directly on the cardiomyocyte and that both nitric oxide and bradykinin are important mediators of this cardioprotection and can initiate signaling pathways that lead to improved cellular function and cell survival. What our data showed was that mitochondria play an important role in this cardioprotection because valsartan can improve ATP availability, essential to preserve left ventricular function (myocardium is highly dependent on ATP produced within the mitochondria to preserve its contractile function, especially during periods of energy shortage, like prolonged ischemia). Regarding remodeling, it is well known that angiotensin II is one of its major determinants, due to increased collagen production (and, therefore, cardiac fibrosis); apoptosis is also important for remodeling and in some animal models valsartan was shown to be anti-apoptotic (der Sarkissian et al., 2003), although other forms of cell death besides apoptosis can be prevalent in cardiac remodeling (Hein et al., 2002); by preserving mitochondrial function and, thus, energy production, during acute ischemia, we hypothesize that valsartan-treated hearts will be less prone to remodeling due to two complementary mechanisms: improved ATP production and decreased angiotensininduced fibrosis.

Using a similar protocol, our research team already demonstrated a positive impact of both carvedilol (Monteiro et al., 2003) and trimatazidine (Monteiro et al., 2004). These studies clearly show that many anti-ischemic drugs act on mitochondrial metabolism during cardiac ischemia, either by accelerating and improving energy production (like carvedilol and valsartan, two drugs that act on the two neurohumural key factors regarding cardiac response to stress: the sympathetic system and the renin-angiotensin-aldosterone system) or by improving the function of specific components of the respiratory chain (like trimetazidine, an anti-ischemic agent without significant haemodynamic effect). Based on these results, we can speculate that behind the good clinical results of many anti-ischemic drugs is an improvement of the cardiac mitochondrial function after an ischemic insult.

In conclusion, results reported in this manuscript allow us to unveil most of the mechanisms for valsartan cardioprotective effects in coronary artery disease patients, mainly in an acute ischemia setting. By promoting a faster and better activity of the mitochondrial phosphorylative system during acute ischemia, valsartan may help to 
overcome one of the most deleterious effects of ischemia (decreased ATP availability), resulting in a positive impact on cardiac mitochondrial function. Therefore, valsartan, by ensuring an improved energy production in ischemic cardiomyocytes, equally allows the improvement of some energy-dependent mitochondrial function parameters, like the maintenance of an adequate electrical potential. Globally, valsartan has a positive effect on mitochondrial function and, therefore, on ischemic cardiomyocytes metabolism. These data can help us to better explain valsartan cytoprotective effect in myocardial ischemia, thus opening new perspectives in the treatment of ischemic heart disease, a leading cause of morbidity and mortality in Western societies.

\section{Acknowledgements}

This study was partially supported by grants from the Coimbra Medical School and the Procardio.

\section{References}

Bauer, J.H., Reams, G.P., 1995. The angiotensin II type 1 receptor antagonists. A new class of antihypertensive drugs. Arch. Intern. Med. $155,1361-1368$.

Cohn, J.N., Tognoni, G., for the Valsartan Heart Failure Trial Investigators, 2001. A randomized trial of the angiotensin-receptor blocker valsartan in chronic heart failure. N. Engl. J. Med. 345, 1667-1675.

Corbucci, G.G., 2000. Adaptive changes in response to acute hypoxia, ischemia and reperfusion in human cardiac cell. Minerva Anestesiol. 66, $523-530$.

Criscione, L., de Gasparo, M., Bühlmayer, P., Whitebread, S., Ramjoue, H.P., Wood, J., 1993. Pharmacological profile of valsartan: a potent, orally active, nonpeptide antagonist of the Ang $\mathrm{II} \mathrm{AT}_{1}$-receptor subtype. Br. J. Pharmacol. 110, 761-771.

der Sarkissian, S., Marchand, E.L., Duguay, D., Hamet, P., deBlois, D., 2003. Reversal of interstitial fibrobalsat hyperplasia via apoptosis in hypertensive rat heart with valsartan or enalapril. Cardiovasc. Res. 57, $775-783$

Gornall, A.G., Bardawill, C.J., David, M.M., 1949. Determination of serum proteins by means of biuret reaction. J. Biol. Chem. 177, $751-766$.

Hein, S., Elsasser, A., Kostin, S., Zimmermann, R., Schaper, J., 2002. Functional disturbances due to structural remodeling in the failing human heart. Arch. Mal. Coeur Vaiss. 95, 815-820.

Kamo, N., Muratsugu, M., Hongoh, R., Kobatake, Y., 1979. Membrane potential of mitochondria measured with an electrode sensitive to tetraphenyl phosphonium and relationship between proton electrochemical potential and phosphorylation potential in steady state. J. Membr. Biol. 49, 105-121.

Kim, S., Yoshiyama, M., Izumi, Y., Kawano, H., Kimoto, M., Zhan, Y., Iwao, H., 2001. Effects of combination of ACE inhibition and angiotensin receptor blocker on cardiac remodeling, cardiac function, and survival in rat heart failure. Circulation 103, 148-154

Kuno, A., Miura, T., Tsuchida, A., Hasegawa, T., Miki, T., Nishino, Y., Shimamoto, K., 2002. Blockade of angiotensin II type 1 receptors suppressed free radical production and preserved coronary endothelial function in the rabbit heart after myocardial infarction. J. Cardiovasc. Pharmacol. 39, 49-57.
Liu, Y.H., Xu, J., Yang, X.P., Yang, F., Shesely, E., Carretero, O.A., 2002. Effect of ACE inhibitors and angiotensin II type 1 receptor antagonists on endothelial NO synthase knockout mice with heart failure. Hypertension $39,375-381$.

Marin-Garcia, J., Goldenthal, M.J., 2002. The mitochondrial organelle and the heart. Rev. Esp. Cardiol. 55, 1293-1310.

Monteiro, P., Duarte, A.I., Moreno, A., Gonçalves, L.M., Providência, L.A., 2003. Carvedilol improves energy production during acute global myocardial ischemia. Eur. J. Pharmacol. 482, 245-253.

Monteiro, P., Duarte, A.I., Gonçalves, L.M., Moreno, A., Providência, L.A., 2004. Protective effect of trimetazidine on myocardial mitochondrial function in an ex-vivo model of global myocardial ischemia. Eur. J. Pharmacol. 503, 123-128.

Multani, M.M., Krombach, R.S., Goldberg, A.T., King, M.K., Hendrick, J.W., Sample, J.A., Baicu, S.C., Joffs, C., de Gasparo, M., Spinale, F.G., 2001a. Myocardial bradykinin following acute angiotensinconverting enzyme inhibition: $\mathrm{AT}_{1}$ receptor blockade or combined inhibition in congestive heart failure? J. Cardiovasc. Pharmacol. Ther. 6, 369-376.

Multani, M.M., Krombach, R.S., Hendrick, J.W., Baicu, S.C., Joffs, C., Sample, J.A., deGasparo, M., Spinale, F.G., 2001b. Long-term angiotensin converting enzyme and angiotensin I-receptor inhibition in pacing-induced heart failure: effects on myocardial interstitial bradykinin levels. J. Card. Fail. 7, 348-354.

Muratsugu, M., Kamo, N., Kurihara, K., Kobatabe, Y., 1977. Selective electrode for dibenzyl dimethyl ammonium cation as indicator of the membrane potential in electrical systems. Biochim. Biophys. Acta 464, $613-619$

National Research Council, 1996. Guide for the Care and Use of Laboratory Animals. National Academy Press, Washington, D.C.

Oliveira, P.J., Esteves, T., Rolo, A.P., Monteiro, P., Gonçalves, L., Palmeira, C.M., Moreno, A.J., 2003. Carvedilol: relation between antioxidant activity and inhibition of the mitochondrial permeability transition. Rev. Port. Cardiol. 22, 55-62.

Palatini, P., Malacco, E., Fogari, R., Carretta, R., Bonaduce, D., Bertocchi, F., Mann, J., Condorelli, M., for the Italian Collaborative Study Group, 2001. A multicenter, randomized double-blind study of valsartan/hydrochlorothiazide combination versus amlodipine in patients with mild to moderate hypertension. J. Hypertens. 19, 1691-1696.

Pfeffer, M.A., McMurray, J.J., Velazquez, E.J., Rouleau, J.L., Kober, L., Maggioni, A.P., Solomon, S.D., Swedberg, K., Van de Werf, F., White, H., Leimberger, J.D., Henis, M., Edwards, S., Zelenkofske, S., Sellers, M.A., Califf, R.M., for the Valsartan in Acute Myocardial Infarction Trial Investigators, 2003a. Valsartan, captopril, or both in myocardial infarction complicated by heart failure, left ventricular dysfunction, or both. N. Engl. J. Med. 349, 1893-1906.

Pfeffer, M.A., McMurray, J.J., Velazquez, E.J., Rouleau, J.L., Kober, L., Maggioni, A.P., Solomon, S.D., Swedberg, K., Van de Werf, F., White, H., Leimberger, J.D., Henis, M., Edwards, S., Zelenkofske, S., Sellers, M.A., Califf, R.M., On behalf of the Valsartan in Acute Myocardial Infarction Trial Investigators, 2003b. Valsartan, captopril or both in myocardial infarction complicated by heart failure, left ventricular dysfunction, or both. N. Engl. J. Med. 349, 1893-1906.

Richer, C., Fornes, P., Domergue, V., de Gasparo, M., Giudicelli, J.F., 2001. Combined angiotensin II AT1-receptor blockade and angiotensin Iconverting enzyme inhibition on survival and cardiac remodeling in chronic heart failure in rats. J. Card. Fail. 7, 269-276.

Rickwood, D., Wilson, M.T., Darley-Usmar, V.M., 1987a. Isolation and characteristics of intact mitochondria - isolation of mitochondria from mammalian cells. In: Darley-Usmar, V.M., Rickwood, D., Wilson, M.T. (Eds.), Mitochondria: A Practical Approach. IRL Press, Oxford, England, pp. 4-5.

Rickwood, D., Wilson, M.T., Darley-Usmar, V.M., 1987b. Isolation and characteristics of intact mitochondria - isolation of mitochondria from mammalian cells. In: Darley-Usmar, V.M., Rickwood, D., Wilson, M.T. (Eds.), Mitochondria: A Practical Approach. IRL Press, Oxford, England, pp. 11-13. 
Stocchi, V., Cucchiarini, L., Magnani, M., Chiarantini, L., Palma, P., Crescentini, G., 1985. Simultaneous extraction and reverse-phase highperformance liquid chromatographic determination of adenine and pyridine nucleotides in human red blood cells. Anal. Biochem. 146, $118-124$.

Ylitalo, K., Ala-Rami, A., Vuorinen, K., Peuhkurinen, K., Lepojarvi, M., Kaukoranta, P., et al., 2001. Reversible ischemic inhibition of $F(1) F(0)$ -
ATPase in rat and human myocardium. Biochim. Biophys. Acta 1504 $329-339$.

Yu, C.M., Tipoe, G.L., Wing-Hon, L.K., Lau, C.P., 2001. Effects of combination of angiotensin-converting enzyme inhibitor and angiotensin receptor antagonist on inflammatory cellular infiltration and myocardial interstitial fibrosis after acute myocardial infarction. J. Am. Coll. Cardiol. 38, 1207-1215. 